\title{
Strategi pemanfaatan limbah bathok kelapa masyarakat Sidomulyo Dusun Kalimeneng Kabupaten Blitar
}

\author{
Ubaidillah $^{1^{*}}$, Neli Ana Sapitri ${ }^{1}$ \\ ${ }^{1}$ UIN Sayyid Ali Rahmatullah, JIn. Mayor Sujadi Timur 46 Plosokandang, Indonesia \\ ${ }^{*}$ Korespondensi (e-mail: ubaidillah830@gmail.com) \\ Received: 31-May-21; Revised: 15- June -21; Accepted: 28- June -21
}

\begin{abstract}
Sid omulyo is the main coconut sup plier village of Blitar City. There is a problem; the coconut shell waste is only used for fuel or become a trash. Then, it ap peared the pud dle that becomes the mosquito lair. It could attack the community health. Based on that problem, there is an effort to utilize the coco nut shell waste through cooperation scheme to gether with creative and home industries entrepreneur. The methods used were: field-observation, collected data, so cialization, up to assistance related to the utilization of coconut shell waste. It was conducted for traditional market up to micro small and medium enterprises or UMKM. The results of this study were: increasing the communities' income. The second, creating the community of co conut shell waste collector, then the th ird is build cooperation to gether with the entrepreneur and clean environment without the mosquito.
\end{abstract}

Keywords: Strategy Step, The Coconut Shell, Market Relation

\begin{abstract}
Abstrak
Sidomulyo merupakan penyuplai utama kelapa di Kota Blitar. Masalahnya, usaha pemanfaatan limbah bathok kelapa hanya dipergunakan sebagai bahan bakar atau dibuang begitu saja. Dampaknya, terdapat genangan air yang menimbulkan berkembangbiaknyajentik nyamuk yang menggangu kesehatan warga. Atas kegelisahan tersebut diupayakan pemanfaatan limbah bathok kelapa melalui skema kerjasama bersama pengusaha industri kreatif dan home industri. Metode yang dilakukan dengan melakukan observasi lapangan, pendataan, sosialisasi hingga pendampingan terkait informasi pemanfaatan limbah bathok kelapa mulai dari pasar tradisional hingga UMKM. Hasilnya, pemanfaatan bathok kelapa menambah penghasilan warga. Kedua, terbentuknya paguyuban pengumpul bathok kelapa dan Ketiga, kerjasama bersama pihak pengusaha dan lingkungan bersih tan pa nyamuk.

Kata kunci: Langkah Strategis, Bathok Kelapa, Relasi Pasar.

How to cite: Ubaidillah, U., \& Sapitri, N. A. (2021). Strateg i peman faatan limbah bath ok kelapa masyarakat Sidomulyo Dusun Kalimeneng Kabupaten Blitar. Penamas: Journal of Community Service, 1(1), 1-7.
\end{abstract}

\section{Pendahuluan}

Upaya pemanfaatan limbah di beberapa daerah di Indonesia telah menjadi model ekonomi kreatif sebagai strategi nilai tambah ekonomi. Semisal pemanfatan limbah batang pisang yang dioalah menjadi bahan dasar pembuatan kertas (Syarifuddin \& Hamzah, 2019). Strategi tersebut juga terjadi pada upaya pengolahan limbah kelapa di desa Sidomulyo kecamatan Bakung Kabupaten Blitar. Hampir setiap warga mempunyai pohon kelapa, kebanyakaan warga hanya menjual isi dari buah kelapa dan meninggalkan limbah kelapa. Limbah kelapa tersebut biasanya digunakan sebagai kayu bakar, atau dibuang begitu saja di halaman rumah warga. Padahal, 
limbah dari pohon kelapa tersebut dapat dimanfaatkan dan menambah penghasilan warga. Semisal pemanfaatan bathok kelapa sebagai arang sebagaimana cara yang sama dilakukan untuk cangkang kelapa sawit (Haryanti A., Norsamsi,Sholiha P.S.F., 2014) Tetapi, tidak semua warga sadar akan hal itu, masih banyak warga yang hanya memanfaatkan limbah kelapa hanya sebagai kayu bakar.

Di sisi lain, warga masih terfokus pada pemanfaatan daun kelapa untuk dijadikan sapu lidi tetapi tidak dengan limbah bathok kelapa di Desa Sidomulyo. Padahal upaya kreatif pemanfaatan kelapa hampir seluruhnya bermanfaat termasuk serabut kelapa (Amin \& Samsudi, 2010). Demikian halnya dengan arang kelapa dapat dimanfaatkan sebagai media menjernihkan air atau filter air melalui karbon aktif yang dihasilkan (Nustini, 2019). Atas dasar kegelisahan itulah skema pemanfaatan limbah bathok kelapa dibuat dalam bentuk rencana stategis yang mungkin dilakukan di tengah kesibukan warga sekitar. Tujuan penelitian ini ingin membuktikan bahwa limbah bathok kelapa dapat dijadikan sebagai penghasilan tambahan dari sekedar menjadi limbah yang tidak berharga. Di sisi lain, limbah kelapa yang terbuang mengakibatkan genangan air yang menyebabkan berkembangbiaknya jentik nyamuk.

Dalam penelitian sebelumnya ditemukan beberapa kemiripan persoalan di mana kelapa merupakan tanaman serba guna yang bernilai ekonomis tinggi. Di sisi lain, kelapa juga banyak dijadikan kopra dan hasil samping dari kopra adalah tempurung yang jarang diolah lebih lanjut, hanya dibeberapa tempat tempurung diolah menjadi arang dengan teknik tradisional dengan nilai ekonomis rendah. Limbah kelapa yang berupa tem purung sebenarnya dapat dijadikan bahan dalam panel akustik (Indrawati \& Suyatno, 2017) Termasuk sebagai bahan pengeras campuran aspal yang dipergunakan untuk jalan (Utomo, 2019). Di sisi lain, peneliti Susilo Indrawati dan Suyanto tempurung kelapa merupakan limbah yang jarang dimanfaatkan, khususnya tempurung kelapa muda. Susilo Indrawati dan Suyanto juga menyatakan tempurung kelapa muda dikeringkan dan dipisahkan dari serabutnya, kemudian dibentuk setengah lingkaran berdeameter $10 \mathrm{~cm}$ dan disusun menjadi panel akustik

Dalam konteks masyrakat Desa Kalimeneng permasalan Internal yang dihadapi adalah minimnya infromasi pemanfaatan limbah bathok kelapa di sekitar warga dusun Kalimeneng mengakibatkan kondisi lingkungan tidak sehat serta keterbatasan meningkatkan sumber nilai ekonomis yang disebabakan oleh beberapa faktor yaitu pertama, minimnya kesadaran masyarakat dalam menjaga lingkungan yang sehat. Kedua, keterbatasan informasi pemanfaatan limbah bathok kelapa. Ketiga, Ketiadaan relasi pasar dari dan oleh warga kepada industri kreatif bathok kelapa. Ke empat, Bagaimana strategi pengumpulan bathok kelapa hingga layak dipasarkan.

Atas dasar pertimbangan persoalan di atas upaya strategi pemberdayaan masyarakat Desa Kalimeneng untuk terus dapat berkembang dari status desa tertinggal, berkembang hingga menjadi desa yang mandiri tentu perlu disiapkan starategi model ketahanan ekonomi yang kreatif dengan memanfaatkan kearifan lokal setem pat dal hal ini limbah bathok kelapa. Dengan adanya upaya tersebut strategi pemberdayaan melaluikegiatan mengolah limbah kelapa merupakan langkah penting 
dari tiga strategi peralihan status desa di atas (Sukarno et al., 2018). Untuk memperoleh hasil capaian yang maksimal maka diperlukan langkah metodologis sebagai berikut.

\section{Metode Pengabdian}

Penelitian ini akan membahas tentang metodologi pemanfaatan bathok kelapa yang merupakan pengabdian berbasis riset kualitatif, dengan metode pengumpulan data obserasi dan wawancara. Data primer diperoleh melalui hasil kuisioner, wawancara, dan observasi lapangan. Bentuk data secara deskriptif melaluipertanyaanyang terkait berapa jumlah limbah batok kelapa, berapa penghasilan warga dari hasil penjulan kelapa serta bagaimana usaha warga dalam memanfaatkan batok kelapa. Lokasi dan tempat Pengabdian riset ini dilakukan selama 1 Bulan setengah di Kecamatan Bakung, Desa Sidomulyo, Dusun Kalimeneng.

\section{Strategi Pelaksanaan}

Melakukan kunjungan ke rumah Pak RW 08 untuk menanyakan mengenai olahan kelapa mulai sapu lidi hingga batok kelapa. Selanjutnya, melaksanakan survey ke beberapa pasar yang menjadi pusat penjualan buah kelapa seperti; Pasar Lorejo, Pasar Suruh wadang, dan Pasar Kademangan. Terakhir, melakukan surery mengunjungi pengrajin bathok kelapa di Tanjungsari-Blitar.

\section{Stratgi Partisipasi Mitra dan Evaluasi}

Dengan adanya pratisipasi mitra hasil yang diharapkan dalam pelaksanaan program adalah dukungan dan kerjasama dengan warga untuk menyukseskan kegiatan. Selanjutnya menyediakan tempat untk pengumpulan bathok kelapa sebelum diambil pengepul sekaligus menyediakan buku dan timbangan untuk mencatat dan menimbang bathok kelapa per warga. Dengan partisipasi tersebut akan tercipta kekompakan untuk keberlangsungan kegiatan kelompokini. Partisipasi di atas tujuan partisipasi masyarakat untuk membentuk lingkar budaya desa (LBD) berdasarkan kearifin lokal yang dimiliki melalui nilai kebersaman, persaudaraan dan kesadaran(Sukiyono etal., 2019)

\section{Hasil Pengabdian}

Berdasarkan hasil survey dari beberapa pasar, hasil dari harga kelapa rata-rata sama yaitu sekitar Rp.3.500,00 s/d Rp.4000,00 dari para petani dari Desa Sidomulyo. Para petani meminta agar harga tersebut berlaku sama (besar dan kecil) dan masih ada serabutnya. Setelah survey dibeberapa paar dan hasilnya sama. Selanjutnya, mencari infromasi terkait pemanfaatan daun kelapa. Setelah sampai di Makam Bung Karno Kota Blitar, ternyata bathok kelapa dapat dimanfaatkan menjadi berbagai kerajinan, misalnya dibuat gantungan kunci, gelas, angkir, tas, dan masih banyak lagi. Menurut pengrajin bathok kelapa mendapatkan kerajinan tersebutada yang dari blitar dan ada yang dari Jogja. Dan setelah perjalanan panjang, akhirnya menemukan pengerajin bathok kelapa di Desa Tanjungsari Kota Blitar. 


\section{Skema Sosialisasi Pemanfaatan Limbah Bathok Kelapa}

Strategi yang dilakukan pertama kali adalah dengan melakukan kegiatan sosialisasi pemanfaatan limbah kelapa kepada pengusahakreatif. Dalam sosialisasi tersebut dijelaskan bahwa bathok kelapa tidak hanya dapat digunakan sebagai kayu bakar saja, tetapi bisa dijual. Warga disana ternyata baru menyadari bahwa bathok kelapa juga bisa jadi uang. Survey kerumah warga RT 01/RW 08 Dusun Kalimeneng DesaSidomulyo, untuk menjelaskan program yang akan dilaksanakan oleh divisi ekonomi. Disini divisi ekonomi menjelaskan bahwa bathok kelapa dapat dibuat seperti gantungan kunci, gelas, tas, dan lain-lain.

Di sisi lain, juga dijelaskan harga per kg bathok kelapa dan juga kriteria yang bisa dibuat kerajinan. Setiap kriteria dihargai berbeda-beda. Dan bathok kelapa yang tidak bisa dibuat untuk kerajinan tetap bisa dijual namun itu digunakan sebagai bahan arang. Setelah mendengar penjelasan dari divisi ekonomi pak RT dan bu RT 01 RW 08 merespon dengan baik dan sangat mendukung dengan apa yang disampaikan oleh divisi ekonomi serta beliau memberikan saran agar divisi ekonomi mensosialisasikan pada saat acara arisan ibu-ibu satu RT.

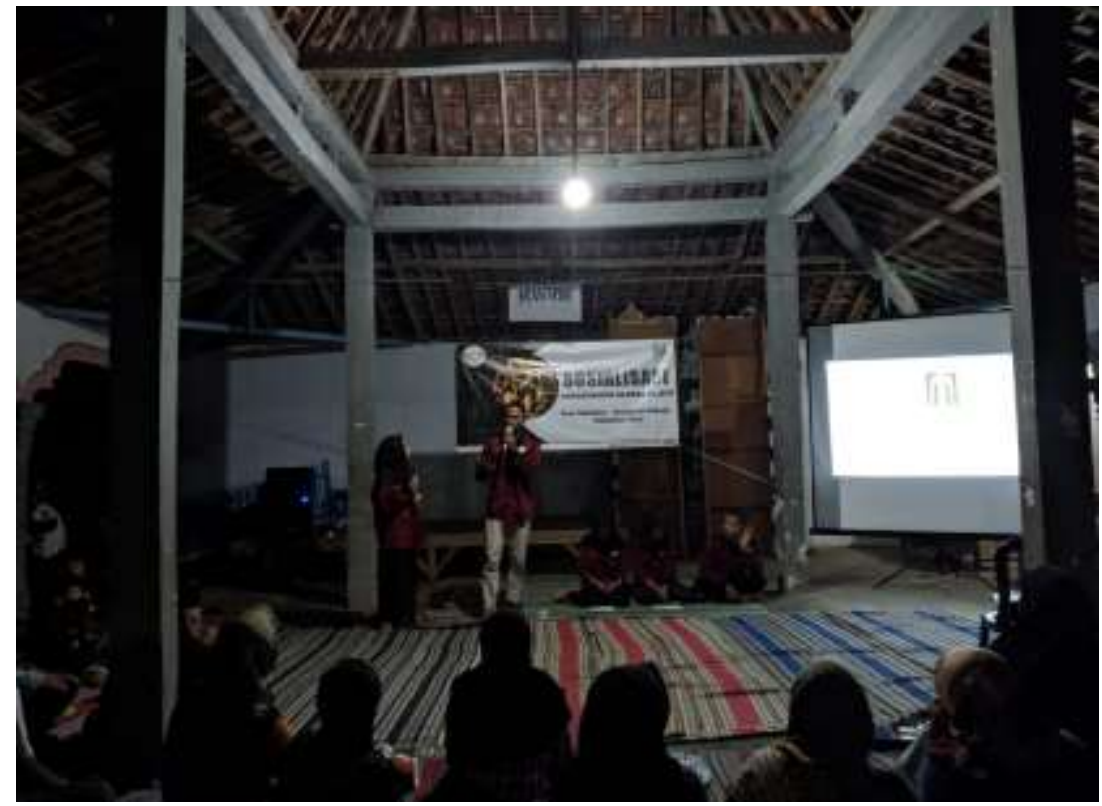

Gambar 1. Kegiatan Sosialisasi Pemanfaatan Limbah Bathok Kelapa

Sosialisasi diacara ibu-ibu arisan di RT 01/RW 08 Dusun Kalimeneng Desa Sidomulyo untuk menyampaikan terkait pemanfaatan bahok kelapa. Setelah divisi ekonomi menjelaskan, ada beberapa warga yang setuju dengan ada juga yang menolak dengan alasan tidak tentu memasak dengan kelapa jadi sulit untuk mendapatkan bathok kelapa. Ada juga yang bilang kalau bathoknya itu sudah dijual bersama kelapanya kepada pengepul kelapa. Tetapi warga yang setuju dengan usulan divisi ekonomi, menanyakan bagaimana caranya agar pengerajin tersebutmengetahui kualitas bathok kelapa dari Dusun Kalimeneng Desa Sidomulyo, dan disini divisi ekonomi menjelaskan bahwa akan membawakan contoh bathok kelapa. Dan salah 
satu warga memberikan beberapabathok kelapa untuk dibawa kepengengrajin bathok kelapa.

Membawa sampel bathok kepengarajin bathok yaitu Bapak Ismarofi, namun menurut beliau bathok yang kami bawa kurang cocok untuk membuat kerajinan dan disarankan untuk dijual dipengusaha arang. Kriteria yang dimau oleh pengerajin bathok kelapa adalah kelapanyaharus tebal dan besar. Sedangkan bathok kelapa dari Dusun Kalimeneng desa Sidomulyo bathoknya kecil-kecil dan juga tipis. Menurut Pak Ismarofi bathok ini akan mudah pecah saat dipotong atau pada saat proses pembuatan kerajinan. Atas saran tersebut maka lokasi pengusaha arang yaitu Pak Sutrisno. Setelah sampai di rumah Pak Sutrisno (pengusaha arang) beliau kaget dengan kedatangan kami, dan kami langsung menjelaskan tujuan kami.

Setelah mendengar penjelasan, beliau setuju untuk membeli bathok kelapa dari sana untuk bahan arang. Pak Sutresno menerima berbagai jenis bathok kelapa, mulai dari yang besar sampai yang hancur pun juga akan dibeli. Harga per kg bathok kelapa dihargai Rp.800,00, namun jika mencapai 1 Ton atau lebih berani membeli dengan harga Rp.850,00/kg. Setelah mendapatkan persetujuan dari pengusaha arang untuk menjual bathok kelapa kesana. Hal ini serupa yang dilakukan oleh masyarakat desa Bantan Air Kabupaten Bengkalis dengan menggunakan pendekatan IPTEK yang lebih inovatif berupa alat kondensor sebagai cara alternative merubah limbah asap tempurung menjadi asap cair (Salam, 2018). Divisi ekonomi langsung mengadakan acara sosialisasi mengenai bathok kelapa. Divisi ekonomi langsung menyebar undangan kepada ketua RW dan RT untuk kegiatan sosialisasi pemanfaatan bathok kelapa. Sasaran divisi ekonomi tidak hanya RT01/RW 08 saja, namun seluruh Dusun Kalimeneng. Tujuan divisi ekonomi mengundang warga se-Dusun Kalimeneng untuk memenuhi target dri pengerajin arang yaitu minimal 30 karung dan juga untuk menambah perekonomian warga.

\section{Strategi Marketing Pemanfaatan Limbah Bathok Kelapa}

Setelah melakukan sosialisasi divisi ekonomi tidak hanya meninggalkan kontak pengusaha arang, namun divisi ekonomi mengontrol seberapa jauh kelanjutan setelahsosialisasi pemanfaatan bathok kelapa, ternyata mendapat respon yang baik dari masyarakat sam pai akan dibelikan kantong kresek perumah untuk mengumpulkan bathok kelapa. Selain itu, ada beberapa warga yang sudah mengumpulkan sampai setengah karung. Untuk tempat pengumpulan bathok kelapa sebelum diambil oleh pengusaha arang, dibuatlan skema pengumpulan bathok kelapa ke dalam tiga bagian besar yaitu disetiap rumah RW. Disetiap titik pengumpulan akan dipilih 1 orang untuk menjadi pencatat berapa banyak setiap warga memperoleh bathok kelapa. Dan untuk pembagian hasilnya berdasarkan banyak atau sedikitnya bathok kelapa yang dikum pulkan. Dari usaha pencapaian strategi di atas perlu tindak lanjut yang bersifat kesinambungan tentu dengan melibatkan instrument kekuatan desa yaitu BUM desa sebagai solusi keberlanjutan usaha yang sudah dihasilkan dan pengelolan potensi desa lainnya secara mandiri untuk kesejahteran yang lebih baik(Helmiati etal., 2017) 


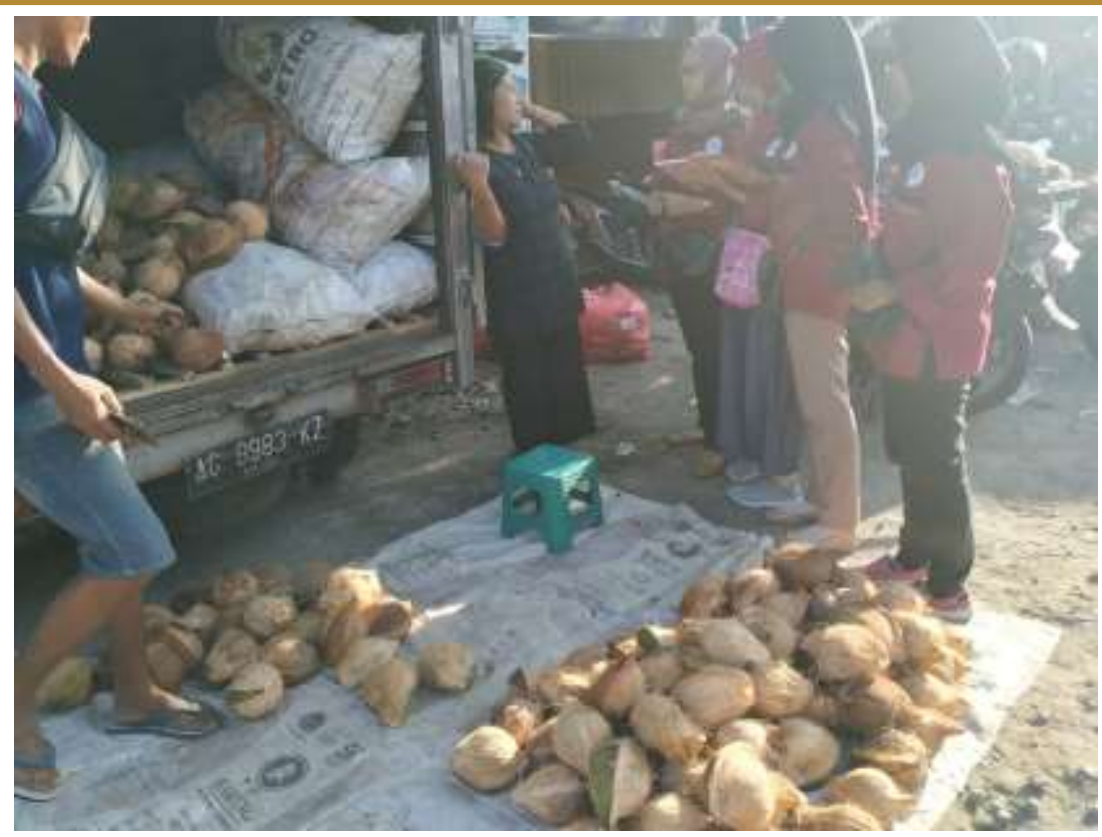

Gambar 2. Strategi Marketing Pemanfaatan Limbah Bathok Kelapa

Dari hasil strategi pemberdayaan ekonomi masyarakat di Dusun Kalimeneng terdapat beberapa indikator keberhasilan yaitu; pertama, sikap dan perilaku masyarakat Desa Kalimeneng berubah dengan lebih peduli terhadap lingkungan dengan menghilangkan genangan air pada limbah bathok kelapa. Kedua, limbah bathok kelapa yang menjadi sampah kini berubah menjadi rupiah dengan upaya klasifikasi bathok kelapa yang menjadi arang dan barang furniture. Ketiga, keterampilan masyarakat mulai terasah dengan informasi beragam olahan bathok kelapa. Terakhir, masyarakat termotivasi untuk mengembangkan bahan olahan lainnya yang menjadi kekayaan alam di dusun kalimeneng, Desa Sidomulyo.

\section{Kesimpulan}

Desa Sidomulyo tepatnya di Dusun Kalimeneng kaya akan ketersediaan sumber alam berupa pohon kelapa. Limbah bathok kelapa yang awalnya hnaya terbengkalai menjadi sampah dan penyakit kini berubah menjadi rupiah dan menciptakan lingkungan bersih dan mencegah serangan penyakit nyamuk. Kehidupan masyarakat desa yang guyub dan rukun adalah potensi eksternal yang mampu memberikan kemudahan dan kemampuan memperoleh hasil capaian pemberdayaan lebih maksimal. Kearifan lokal masyarakat berupa alam, nilai buda dan adat istiadat adalah manifestasi pemberdayaan yang terus dapat dikembangkan untuk kebaikan dan kesejahteraan masyarakat desa sebagai pusat ketahanan pangan dan moralitas.

\section{Ucapan Terimakasih}

Dengan terlaksananya kegiatan pengabdian di atas ungkapan terimakasih penulis sampaikan kepada pihak perangkat desa dan masyrakat yang dengan terbuka memberikan kesempatan untuk berkerjasama memajukan desa melalui berbagai 
ikhtiar pengembangan ekonomi masyarakat yang dapat dilakukan. Selanjutnya kepada pihak LP2M yang telah mewadahi program pengabdian ini dapat berjalan dengan baik dan lancar. Kedepan perlu dilakukan penguatan dan pengembangan disektor kesehatan mengingat minimnya kesadaran kebersihan dan kesehatan desa.

\section{Referensi}

Amin, M., \& Samsudi, R. (2010). Pemanfaatan limbah serat sabut kelapa sebagai bahan Pembuat helm pengendara kendaraan roda dua. Prosiding Seminar Nasional, 1-5. http://jurnal.unimus.ac.id/index.php/psn12012010/article/view/96

Haryanti A., Norsamsi,Sholiha P.S.F., P. N. P. (2014). Studi Pemanfaatan Limbah Padat Kelapa Sawit. Jurnal Konversi, 3(2), 20-22.

Helmiati, Umar, J., Nurharyadi, Ahadi, I. N., Andriawati, M. R., Noviansyah, D., Hidayatullah, A., Hasanah, Gusrianty, E., Santoso, C., Saputra, A. C., Alfani, N., Putranto, F., Dewi, F. S., \& Saputri, A. R. (2017). BUM Desa. Kementrian Desa, Pembangunan Daerah Tertinggal dan Transmigrasi Republik Indonesia.

Indrawati, S., \& Suyatno, S. (2017). Pemanfaatan Limbah Tempurung Kelapa Muda sebagai Alternatif Material Akustik. Jurnal Fisika Dan Aplikasinya, 13(3), 115. https://doi.org/10.12962/j24604682.v13i3.2842

Nustini. (2019). Pemanfaatan Limbah Tempurung Kelapa Menjadi Arang Tempunung Kelapa dan Granular Karbon Aktif Guna Meningkatkan Kesejahteraan Desa Watuduwur, Bruno, Kabupaten Purworejo_Nustini _ Asian Journal of Innovation and Ent. Asian Journal of Innopation and Enterpreneurship , 4(3), 217-226.

Salam, A. H. (2018). Pkm - Pengusaha Arang Tempurung Kelapa Desa Bantan Air Kecamatan Bantan Kabupaten Bengkalis Provinsi Riau. Dinamisia: Jurnal Pengabdian Kepada Masyarakat, 2(2), 98-102. https://doi.org/10.31849/dinamisia.v2i2.1918

Sukarno, G., Soedarto, T., Tranggono, D., Takarini, N., Kustini, Emerldien, Z., Cempaka, G. G., Izaak, W. C., Alit, R., Anwar, M., Sunarsono, R. J., Mahanani, A. E. E., Hendrarini, H., Septianto, Y., Huda, S., Hidayat, S. I., \& Fauzi, A. (2018). Data dan Informa si Manfaat Dana Desa di Provinsi Jawa Timur. Kementrian Desa, Pembangunan Daerah Tertinggal dan Transmigrasi Republik Indonesia. https://doi.org/10.1017/CBO9781107415324.004

Sukiyono, K., Novanda, R. R., Priyono, B. S., Widiono, S., Arianti, N. N., Yuliarso, M. Z., Osira, Y., Nasihu, M., \& Jannah, M. (2019). Inovasi Desa Membangun: Pemanfaatan Data IDM. Kementrian Desa, Pembangunan Daerah Tertinggal dan Transmigrasi Republik Indonesia.

Syarifuddin, H., \& Hamzah, H. (2019). Prospek Pemanfaatan Limbah Batang Pisang Dalam Mendukung Ekonomi Kreatif Masyarakat Ramah Lingkungan. Dinamisia: Jurnal Pengabdian Kepada Masyarakat, 3, 27-34. https://doi.org/10.31849/dinamisia.v3i2.2868

Utomo, N.-. (2019). Pemanfaatan Limbah Tempurung Kelapa Sebagai Material Pengisi Pada Campuran Perkerasan Jalan. Jurnal Envirotek, 11(1), 59-65. https://doi.org/10.33005/envirotek.v11i1.1363 